\title{
Understanding Care: Introductory Remarks
}

\author{
Franziska Krause and Joachim Boldt
}

"Care" is without doubt among the most important concepts in healthcare. The very word "healthcare" bears witness to this fact, indicating what the healthcare system as a whole and the individual actions taking place within healthcare are all about — namely, to provide care. The concept of care plays an important role for the professional identity of caregivers, and it is part of the expectation of care receivers. This can easily be forgotten given that in public and academic discourse, issues such as costs, prevention, the just distribution of scarce resources and the patient's personal responsibility often figure more prominently than care.

Care is not only a descriptive concept, it also conveys a normative orientation. The term "care" enables one to evaluate different courses of action in healthcare. What is more, different courses of action can correspond more or less closely to what one perceives as good care. As there are standards and guidelines for and best practices of good care, care providers can ask themselves whether what they do constitutes good care. The question of whether the healthcare system as a whole as well as specific

F. Krause $(\bowtie) \cdot \mathrm{J}$. Boldt

Department of Medical Ethics and the History of Medicine, University of Freiburg, Freiburg, Germany 
regulations and practices within healthcare live up to the ideals of good care is always subject to debate.

For example, one may ask whether it is good care in midwifery to allow mothers to give birth at home and to offer them support in doing so. Many factors must be taken into account in order to come to a conclusion-from the percentage of home and hospital births that involve severe incidents, to the experiences of mothers giving birth in both situations, to the costs of these two alternatives. These factors are related to different norms and may point in different directions. In order to find ways to proceed, one has to weigh these norms, including the well-being of mother and child, the economic and societal sustainability of healthcare provisions, and parents' preferences.

Socioeconomic stability may interfere with good care in individual cases, since, for example, the amount of time care providers can allocate to individuals is limited by the number of cases they are expected to manage. Determining what constitutes good care is hence usually a matter of finding reasonable compromises. In healthcare settings, a typical compromise involves finding a balance between optimal care for individuals on the one hand and the institutional demands of providing care to many care receivers over long periods of time as well as the limits of what can legitimately be asked of individual care providers on the other.

Approaches to the ethics of care have shown that care can indeed be understood as an overarching normative concept that integrates different normative orientations. In the current literature, the unifying role of care has been stressed, first and foremost, with regard to personal, dyadic relations as well as with regard to justice and political theory more generally (Conradi 2001; Groenhout 2004; Held 2006; Pettersen 2008; Pulcini 2013; Sevenhuijsen 1996). These approaches can be applied to healthcare. For example, if there is a conflict between care for the well-being of an individual mother and her child and the just allocation of institutional resources, the latter orientation can be understood as an attempt to safeguard the conditions that enable professional care in individual cases. Although protecting the well-being of an individual mother and her child is a prime example of caring, securing institutional socioeconomic stability can be understood as serving the prior aim of caring as well, since the ability to provide professional care in individual cases presupposes 
institutional stability. Making use of care as an overarching normative concept can guide this process of determining the best compromises. Institutional demands that cannot be justified on the basis of maintaining the care institution's socioeconomic stability may be rejected if they interfere with good care in individual cases.

\section{Defining Care}

In order to understand care, one may start by attempting to devise a general definition of this term. Such a definition of care must necessarily be broad if it is to cover as many important aspects of the phenomenon as possible. Care in healthcare comprises many elements including the physical interactions between care providers and patients, the observation of hygiene requirements and the completion of paperwork. Joan Tronto and Bernice Fisher have offered an influential definition that classifies as care all activities that help to "maintain, continue and repair 'our' world so that we can live in it as well as possible" (Tronto 1993, p. 40).

This definition can be fruitfully adapted to the healthcare context by replacing the term "activity" with "action", which specifically indicates goal-directedness and intentionality. Healthcare activities are triggered by patient needs and requests; they follow professional obligations, and are shaped by institutional demands. Thus, activities in this field are usually goal-directed, which is to say they are actions rather than activities. In the same vein, the verbs "maintain, continue, repair" may be changed to "maintain, improve, restore". While the first list describes the relations between people and all manner of entities, the second is tailored to actions that are directed towards humans and human health. On this basis, care in healthcare can be defined as follows:

\section{Care in healthcare is a set of relational actions that take place in an institutional context and aim to maintain, improve or restore well-being. ${ }^{1}$}

This definition brings to the fore three main aspects and characteristics of care that are of specific relevance in the healthcare system: 
Relationality Personal relations are at the heart of care in healthcare, where the paradigm of care is the relationship between a person who gives care and another who receives care. According to this paradigm, relationality is understood as the ongoing verbal and non-verbal communicative process between physically present caregivers and care receivers. This presupposes attitudes like attentiveness and responsivity, which can have a decisive impact on care situations. The way patients perceive and react to the prospect of an unpleasant procedure can change significantly if the caregiver approaches the patient in a caring manner. Nonetheless, relationality in healthcare can also be less communicative and personal. For instance, in the case of surgery, it may be limited to the physician's physical intervention into a patient's body. In other instances, such as in telemedicine, care may take place without physical closeness between the caregiver and care receiver. Sometimes the relationality of care might even be completely invisible to observers. For example, when a physician completes a patient's files, there is no visible direct relation to the patient, although the intentions of this action are clearly relational.

Institutionality Care in healthcare is care in an institutionalised and professionalised context. In contrast to care in a private context, care actions in a healthcare setting are often standardised and subject to assessment. This institutional setting can be the source of normative tensions. For example, institutional rules and regulations that are only indirectly connected to the well-being of patients, such as doing paperwork, must be implemented in the daily routines of caregivers even though this diminishes their ability to directly engage with patients. Along the same lines, the rules and regulations concerning bedside caregiving often need to be adjusted to the needs of individual patients and their situation. It is unreasonable to expect that care can be fully standardised, which is to say that to a certain degree, care regulation will always have to leave room for individual, context-sensitive decisions. These normative tensions notwithstanding, regulation and standardisation can in many cases be regarded as being part of providing care for patients, since they enable, for instance, the long-term stability of healthcare systems and the just allocation of healthcare resources. 
Well-being Care in healthcare is directed at those who are ill and at those who are at risk of becoming ill. In some cases, caring for a patient may simply mean curing that person, that is restoring health. In many other cases, such as chronic diseases and situations at the end of life, caring involves maintaining and improving the well-being of the patient to the extent to which this is still possible. Maintaining well-being in these cases is rooted in ongoing relational processes between caregivers and care receivers. As part of these processes, the understanding of well-being must be continuously adjusted, allowing caregiving to proceed in accordance with the wishes of the care receiver. Thus in principle, respecting patient autonomy does not conflict with caring for the patient's well-being.

At the same time, lending an ear to the patient might turn her initial denial into a willingness to attempt a new therapy. Care, therefore, inevitably involves the possibility of indirectly influencing a patient's will. What is more, there are instances of care where the current will, for example, of a dementia patient does not correspond to his overall well-being or his former will. In such cases, care might involve practices that directly influence the patient's will. In this context, it can be difficult to draw clear distinctions between manipulative actions that transgress the boundaries of care and those actions that still fall within the limits of care.

\section{Understanding Care}

As the aforementioned aspects of care make clear, a number of tensions and ambivalences emerge within the notion of care. Although a general definition of the term care can provide a better impression of the range of actions that this term covers, it will not help identify and normatively categorise these tensions, nor find ways to deal with them. However, the fact that it is difficult to come up with a precise definition of care does not imply that it is impossible to point out prototypical examples of care practices or to delineate a spectrum of more or less typical instances of care activities (Mol et al. 2010). To invoke a linguistics textbook example, one can name prototypical examples of objects that fall under the term 
"bird" or "animal" and give less common examples, such as penguins and corals, respectively, even if precisely defining these terms proves impossible.

In order to gain a better understanding of the meaning of care in healthcare in this sense, definitions must be supplemented by descriptions and analyses of concrete care practices. Referring to the tensions mentioned above, questions emerge that can only be answered with reference to concrete cases. For example: Can one's actions still be understood as being part of an ongoing communicative process with the patient? When do daily institutional routines support adequate caregiving, and when do they hinder giving care? Are one's actions still in line with what the patient wants and needs? This book supplies both reflections on general characteristics and definitions of care, and case studies that point to and analyse tensions within the notion of care in different healthcare settings.

\section{Framing Care}

Part one of this book deals with traditions of care theory, philosophical and anthropological approaches to care, and care as an overarching normative concept. Conradi highlights similarities between the notions and intentions of today's care ethics and those of Jewish social reform movements of the late nineteenth and early twentieth centuries in Germany. With regard to philosophical approaches, the book focuses on hermeneutic and phenomenological theories. The characteristics of personal relations, their inherent normativity and interpretations of human interaction have always been at the centre of these theories. Freter, in his contribution, follows the phenomenological tradition and focuses on the notion of the "appeal" that a person in need unwittingly directs at a potential caregiver, using the story of the Good Samaritan as a paradigmatic example. Maio shows how care ethics can be connected to central themes of the hermeneutic tradition, as exemplified by Paul Ricoeur. Care is often assumed to be an antagonistic concept to respect for autonomy. Referring to Ricoeur's concept of the self, Boldt argues instead that an adequate understanding of care necessarily incorporates respect for autonomy and 
vice versa. Krause highlights relationality and responsibility as parts of care. She turns to the case of commercial surrogacy and shows how care ethics and Emmanuel Levinas' notion of the Other add important and often neglected aspects to the ethical evaluation of surrogacy.

\section{Situated Care}

The second part of the book focuses on care in different healthcare settings and analyses cases that do not initially seem to fit within the care paradigm. Typically, these situations pose a challenge to any kind of clear ethical solutions. For example, as Driessen discusses, caring for persons with dementia in residential care homes may comprise elements of "working on the will" of the care receiver in order to align what the resident wants with what the caregiver deems necessary for the person's well-being. Haeusermann also addresses dementia care, describing care practices in the first German dementia village and analysing ambivalences between regulation and freedom, and the constant oscillation between social inclusion and exclusion. On the basis of the current Flemish regulation on the use of seclusion cells in psychiatric institutions, Opgenhaffen suggests that while caregivers should not be overwhelmed or blinded by regulation, regulation should not prematurely impose a rational-objective mode on care. Instead, he spells out how seclusion regulation and care could fruitfully co-exist. Skeide describes witnessing as the relational and environmentally structured strategy of midwives in Germany and France. Being able to witness can be an integrating experience or have an alienating effect. In either case, Skeide establishes that clinical settings tend to delimit witnessing as a midwifery care practice. Pei-Yi Liu's chapter focuses on providing care in the actual homes of diabetes patients. In doing so, she traces the ethical dilemmas and challenges healthcare professionals face when dealing with a chronic illness in homecare settings. She shows that nurses' care tasks alternate between notions of patient autonomy and professional authority-two concepts that at times seem unbridgeable. Kohlen contends that the specific care knowledge and care perspective of nurses is underrepresented in the clinical institutional communication, possibly resulting in harm for patients. On the basis of 
studies in nursing ethics, she examines the ethical problems faced by nurses providing hospital care and their participation in hospital ethics committees over the last 30 years. Van der Meide uses the conceptual tool of the "three dimensional space", introduced by the philosopher and sociologist Henri Lefebvre, in order to describe and delineate the humanising and dehumanising effects of care in the hospital. She shadowed older patients during their stay in the hospital. Their experience of the hospital environment leads to feelings of "not fitting in" and "not belonging to".

All of the contributions in this book highlight the role of care in healthcare. They cannot and do not intend to provide an exhaustive overview of the field. Nonetheless, we are convinced that they give valuable insights into core characteristics as well as tensions and ambivalences of the notion of care in healthcare.

\section{Note}

1. This definition has been discussed and developed jointly by many contributors of this book in the course of a workshop on care in healthcare held in Freiburg in September 2015 (Joachim Boldt, Annelieke Driessen, Björn Freter, Tobias Häusermann, Franziska Krause, Pei-Yi Liu, Tim Opgenhaffen, Annekatrin Skeide).

\section{References}

Conradi, E. (2001). Take Care. Grundlagen einer Ethik der Achtsamkeit. Frankfurt a.M.: Campus.

Groenhout, R. E. (2004). Connected Lives. Human Nature and an Ethics of Care. Lanham: Rowman \& Littlefield.

Held, V. (2006). The Ethics of Care. Personal, Political and Global. Oxford: Oxford University Press.

Mol, A., Moser, I., \& Pols, J. (2010). Care in Practice. On Tinkering in Clinics, Homes and Farms. Bielefeld: transcript.

Pettersen, T. (2008). Comprehending Care. Lanham: Lexington Books.

Pulcini, E. (2013). Care of the World. Fear, Responsibility and Justice in the Global Age (K. Whittle, Trans.). Dordrecht: Springer. 
Sevenhuijsen, S. (1996). Citizenship and the Ethics of Care. Feminist Considerations on Justice, Morality and Politics. London: Routledge.

Tronto, J. C. (1993). Moral Boundaries. A Political Argument for an Ethics of Care. New York: Routledge.

Open Access This chapter is licensed under the terms of the Creative Commons Attribution 4.0 International License (http://creativecommons.org/licenses/ by/4.0/), which permits use, sharing, adaptation, distribution and reproduction in any medium or format, as long as you give appropriate credit to the original author(s) and the source, provide a link to the Creative Commons license and indicate if changes were made.

The images or other third party material in this chapter are included in the chapter's Creative Commons license, unless indicated otherwise in a credit line to the material. If material is not included in the chapter's Creative Commons license and your intended use is not permitted by statutory regulation or exceeds the permitted use, you will need to obtain permission directly from the copyright holder.

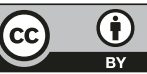

